\title{
sciendo
}

\section{DIETARY BIOTECHNOLOGICAL AJUGA REPTANS EXTRACT IN POST WEANING PIGLETS: EFFECTS ON GROWTH PERFORMANCE, OXIDATIVE STATUS AND IMMUNE PARAMETERS}

\author{
Carlo Corino ${ }^{1}$, Michel Prost $^{2}$, Grazia Pastorelli ${ }^{3}$, Sara Chiapparini ${ }^{1}$, Raffaella Rossi ${ }^{1 \bullet}$ \\ ${ }^{1}$ Department of Health, Animal Science and Food Safety, Università degli Studi di Milano, \\ Via Celoria 10, 20133 Milan, Italy \\ ${ }^{2}$ Laboratoires SPIRAL, 3, Rue des Mardors 21560 Couternon (Dijon), France \\ ${ }^{3}$ Department of Veterinary Medicine, Università degli Studi di Milano, \\ Via Celoria 10, 20133 Milan, Italy \\ •Corresponding author: raffaella.rossi@unimi.it
}

\begin{abstract}
The effect of dietary supplementation with a biotechnological extract of Ajuga reptans on growth performance, oxidative status and immune parameters was evaluated in post weaning piglets. At weaning, 120 piglets with an average live weight of $8.1 \pm 1.3 \mathrm{~kg}$, were assigned to one of three experimental groups. The first group was fed a control diet $(C)$. The second and third groups were fed the same diet supplemented with $5 \mathrm{mg}$ (T1) and $10 \mathrm{mg}$ (T2) of teupolioside/kg feed from a biotechnological plant extract. Growth performances were recorded and blood samples were collected at the beginning, at 14 days, and at the end of the trial (56 days). Serum biochemical parameters, oxidative status and immunoglobulin titres were determined. Average daily gain tended to be higher $(\mathrm{P}=0.057)$ and live weight was higher in piglets $(\mathrm{P}<0.05)$ fed with different amounts of plant extract (T1 and T2) than the controls. The production of reactive oxygen metabolites (ROMs) was higher $(\mathrm{P}<\mathbf{0 . 0 5})$ in the control group than in the groups receiving teupolioside (T1 and T2). Concentration of serum immunoglobulin of class $\mathrm{G}$ improved $(\mathrm{P}<0.001)$ in piglets fed the $\mathrm{T} 1$ and $\mathrm{T} 2$ diets than the controls. Overall, the results suggested that the biotechnological extract of Ajuga reptans containing teupolioside has an antioxidant and immunomodulant effect.
\end{abstract}

Key words: biotechnological extract, piglet, oxidative status, immunoglobulin

Antimicrobial resistance is an important concern for both animal and human health (WHO, 2017). Approximately, 75\% of the antimicrobials sold, including those for human consumption, are intended for animals (67\% in USA, FDA, 2013). Antimicrobials are used in intensively farmed animals for disease prevention and growth promotion effect. The use of antibiotics has been linked with the development of resistant bacteria in chickens and swine gut microbiota (Brüssow, 2017; 
Looft et al., 2012). Van Boeckel et al. (2015) estimated that the global average annual consumption of antimicrobials per kilogram of animal produced was: $45 \mathrm{mg} \cdot \mathrm{kg}^{-1}$ for cattle, $148 \mathrm{mg} \cdot \mathrm{kg}^{-1}$ for chickens and $172 \mathrm{mg} \cdot \mathrm{kg}^{-1}$ for pigs. Italy, where the present study was carried out, has the third highest use of antibiotics in livestock in Europe (ESVAC, 2016).

According to the World Health Organization, the reduction in antimicrobial consumption cannot be delayed. It is thus essential to find new strategies to support animal health and growth performances. Dietary integration with bioactive molecules from natural sources is a sustainable way to reduce the use of antimicrobial and synthetic additives.

Some studies have reported that dietary supplementation with natural extracts in swine and poultry production lead to a better growth performance compared with antimicrobials (Kamel, 2001; Gheisar and Kim, 2018). Phenylpropanoid glycosides (PPGs) belong to the largest group of bioactive molecules in plants and derive mainly from phenylalanine synthesized by a metabolic pathway, which is efficient only in microorganisms and plants (Sangwan et al., 2001). Phenylpropanoid glycosides have shown several biological activities such as antitumoral, antiviral, anti-inflammatory, antibacterial, antioxidative, and free radical scavenging (Dembitsky, 2005). PPGs are thus a very interesting group of molecules for producing immunostimulant, hepatoprotective, antimicrobial, and antinflammatory phyto-preparations (Korkina et al., 2006).

In the group of PPGs, teupolioside (also known as Lamiuside A) is a promising biologically active compound from Ajuga reptans (Di Paola et al., 2009). Teupolioside is structurally characterized by caffeic acid and 4,5 hydroxyphenylethanol bound to a $\beta$-[D]-glucopyranoside through ester and glycosidic links respectively. Two other carbohydrates, i.e. rhamnose and galactose, are linked in sequence to the glucose molecule (Figure 1).

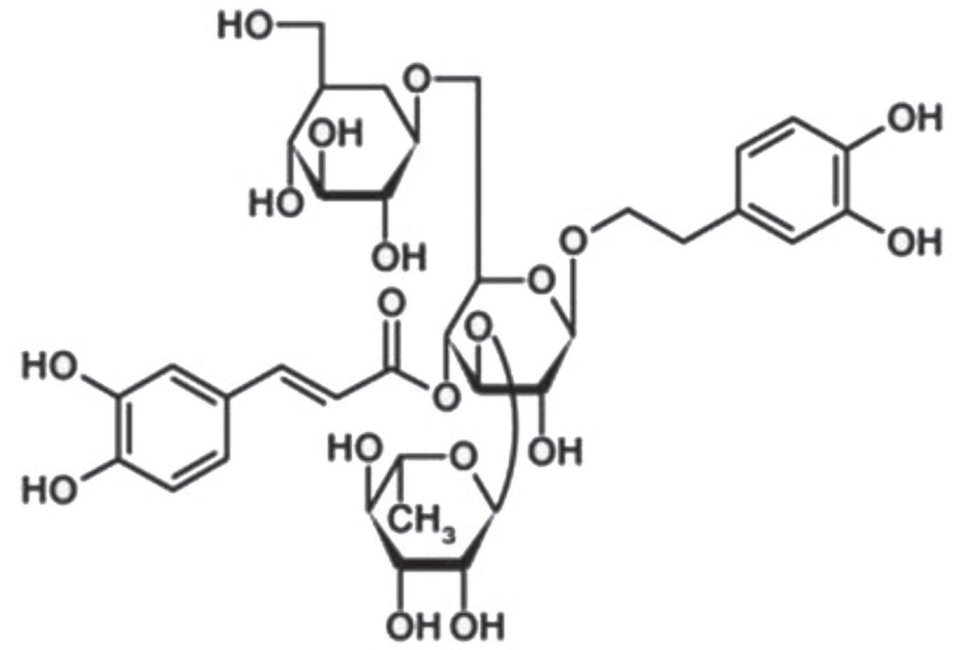

Figure 1. Chemical structure of teupolioside (Di Paola et al., 2009) 
Teupolioside is a secondary metabolite produced in order to protect the plant from UV radiation. From a technological point of view, it is difficult to extract this molecule using industrial methods due to its low content in the whole plant. In fact, the chemical synthesis of the molecule, due to the structure of teupolioside, is complex and very expensive. The Biotecnological Research Institute (I.R.B. S.p.A, Altavilla Vicentina, Italy) has developed a platform for the production of teupolioside using cell cultures in suspension of Ajuga reptans. The biotechnological processes also improve the safety profile and guarantee the highly standardized composition of the extract, thus reducing the environmental impact (Dal Toso and Melandri, 2009).

The aim of the present study was to investigate the effects of dietary supplementation with teupolioside produced by cell cultures of Ajuga reptans (Laminaceae spp.) on growth performance, oxidative status and immunological parameters in post weaning piglets.

\section{Material and methods}

\section{Animals and experimental design}

The animals used in this experiment were cared for following the European Union guidelines (No. 2010/63/EU) and approved by the Italian Ministry of Health. One hundred and twenty weaned piglets (Goland), half castrated males and half females, aged $24 \pm 2$ days, were randomly selected and divided into three experimental groups, balanced for body weight (BW) and gender. During the period of adaptation (7 days), the piglets received a commercial diet for ad libitum consumption. After 7 days of adaptation, at an average body weight of $8.1 \pm 1.3 \mathrm{~kg}$, the piglets were assigned to three dietary treatments ( 8 piglets per pen; 5 pens per treatment) and reared in an environmentally-controlled room (average temperature $26^{\circ} \mathrm{C}$ and relative humidity $60 \%$ ). The control group (C) received a commercial diet, and groups $\mathrm{T} 1$ and T2 received the same diet supplemented with the biotechnological plant extract in order to ensure $5 \mathrm{mg}$ or $10 \mathrm{mg}$ teupolioside per $\mathrm{kg}$ feed. The dosage of teupolioside in the present study was chosen on the basis of the dosage used in humans (EP 1 997501 A2). The plant extract is produced by cell cultures of Ajuga reptans (Laminaceae spp.) and prepared on an industrial scale by a standardised procedure (I.R.B. s.r.l., Altavilla Vicentina, Vicenza, Italy). To prevent oxidation, the supplement was microencapsulated within a protective matrix of hydrogenated vegetable lipids using spray cooling technology (Sintal Zootecnica, Isola Vicentina, Vicenza, Italy). The experimental diets were formulated to meet the requirements for all nutrients (NRC, 1998). The dietary integration was mixed in the mash feed, according to the defined dosage. The composition of the experimental diets according to the piglets' physiological status is reported in Table 1 . The animals had free access to water and were fed ad libitum. The experimental trial lasted 56 days. Piglets were weighed at the beginning and at the end of the trial. The health status of the piglets was recorded daily. The amounts of feed offered and refused were recorded daily to calculate the feed intake. These data were used to calculate the average daily gain (ADG), gain feed ratio (G:F), and average daily feed intake (ADFI) of each pen. 
Table 1. Composition of the experimental diets ( $\mathrm{g} / \mathrm{kg}$, as-fed basis)

\begin{tabular}{|c|c|c|}
\hline Live weight range & $8-15 \mathrm{~kg}$ & $15-30 \mathrm{~kg}$ \\
\hline \multicolumn{3}{|l|}{ Ingredient } \\
\hline steam-rolled corn & 280 & 180 \\
\hline corn yellow & 150 & 200 \\
\hline barley & 150 & 200 \\
\hline wheat middlings & 80 & 80 \\
\hline dried whey & 50 & 20 \\
\hline soy protein concentrate, $64 \% \mathrm{CP}$ & 40 & 44 \\
\hline soybean meal, $48 \% \mathrm{CP}$ & 60 & 80 \\
\hline fish meal, $70 \% \mathrm{CP}$ & 28 & - \\
\hline rice protein meal, $65 \% \mathrm{CP}$ & 24 & 20 \\
\hline dextrose & 25 & 10 \\
\hline wheat bran & 30 & 80 \\
\hline soy oil & 30 & 30 \\
\hline experimental supplement ${ }^{1}$ & 1 & 1 \\
\hline vitamin-mineral premix ${ }^{2}$ & 34 & 34 \\
\hline dicalcium phosphate & 10 & 14 \\
\hline L-Lysine $\times \mathrm{HCl}$ & 5 & 4 \\
\hline preservative $^{3}$ & 3 & 3 \\
\hline \multicolumn{3}{|l|}{ Calculated chemical composition ${ }^{4}$} \\
\hline crude protein & 206.1 & 195.4 \\
\hline ether extract & 83.3 & 75.6 \\
\hline crude fiber & 30.9 & 39.9 \\
\hline ash & 61.3 & 65.9 \\
\hline lysine & 13.1 & 11.9 \\
\hline methionine + cysteine & 7.9 & 7.2 \\
\hline threonine & 8.5 & 7.7 \\
\hline tryptophan & 2.6 & 2.4 \\
\hline
\end{tabular}

'Quantities of plant extract standardized for teupolioside provided per $1 \mathrm{~kg}$ of complete diet: 0 (maltodextrins), for control, $5 \mathrm{mg}$ teupolioside (T1), and $10 \mathrm{mg}$ teupolioside (T2) groups respectively.

${ }^{2}$ Provided per $1 \mathrm{~kg}$ of complete diet: Ca $2.8 \mathrm{~g}, \mathrm{P} 0.14 \mathrm{~g}, \mathrm{Na} 1.33 \mathrm{~g}$, vit. A $16000 \mathrm{IU}$, vit. $\mathrm{D}_{3} 2000 \mathrm{IU}$, vit. E $175 \mathrm{IU}$, vit. $\mathrm{K}$ (menadione sodium bisulfite) $3.8 \mathrm{mg}$, vit. $\mathrm{B}_{1} 4.9 \mathrm{mg}$, vit. $\mathrm{B}_{2} 9.8 \mathrm{mg}$, calcium D-pantothenate $40 \mathrm{mg}$, niacin $57.8 \mathrm{mg}$, vit. $\mathrm{B}_{12} 0.09 \mathrm{mg}$, vit. $\mathrm{B}_{6} 7.7 \mathrm{mg}$, folic acid $3.4 \mathrm{mg}$, biotin $0.33 \mathrm{mg}$, choline chloride 1000 $\mathrm{mg}, \mathrm{Zn}(\mathrm{ZnO}) 85 \mathrm{mg}, \mathrm{Cu}\left(\mathrm{CuSO}_{4}\right) 85 \mathrm{mg}, \mathrm{Mn}(\mathrm{MnO}) 108 \mathrm{mg}, \mathrm{Fe}\left(\mathrm{FeCO}_{3}\right) 470 \mathrm{mg}, \mathrm{I}(\mathrm{KI}) 3.85 \mathrm{mg}, \mathrm{Co}\left(\mathrm{CoSO}_{4}\right)$ $1.4 \mathrm{mg}$, $\mathrm{Se}\left(\mathrm{as} \mathrm{Na}_{2} \mathrm{SeO}_{3}\right) 490 \mu \mathrm{g}$. Premix containing calcium formiate, Saccharomyces cerevisiae, sodium chloride, barley, butyric acid, dL-tryptophan, dL-methionine, L-treonine.

${ }^{3}$ Composition per $1 \mathrm{~kg}$ of complete feed: formic acid $0.3 \mathrm{~g}$, lactic acid $1.1 \mathrm{~g}$, colloidal silica carrier $1.6 \mathrm{~g}$.

${ }^{4}$ Calculation based on INRA (2004).

\section{Sample collection}

Blood samples were obtained, by anterior vena cava puncture before the morning feeding, from 10 randomly selected castrated male piglets per treatment (2 piglets/ 
pen), at the beginning of the trial, and at days 14 and 56. The blood samples were collected in $10 \mathrm{~mL}$ vacutainer glass tubes (Venoject ${ }^{\circledR}$, Terumo Europe N.V., Leuven, Belgium) and immediately placed on ice. Serum was harvested by centrifugation $\left(8,500 \times \mathrm{g}\right.$ for $\left.15 \mathrm{~min}, 4^{\circ} \mathrm{C}\right)$ and stored at $-80^{\circ} \mathrm{C}$ pending analysis.

\section{Determination of antioxidant activity of plant extract}

The antioxidant activity of the biotechnological extract of Ajuga reptans, was evaluated using the Kit Radicaux Libres (KRL) biological test (Prost, 1992). This exvivo test is based on free radical-induced hemolysis and tests the antioxidant capacity of several molecules in a biological condition. A control blood sample was used as the biological medium (Astra for medics S.R.L, Milan, Italy). The direct effect of the phenolic compounds on the control blood was tested without free radical addition, also verifying that the blank did not present any interference (cytotoxic assays). The phenolic compounds were dissolved in aqueous solution at different concentrations.

Blood solutions were incubated at $37^{\circ} \mathrm{C}$ with different ranges of concentration (from 0 to $1 \mathrm{mg}$ by liter of reaction medium) of the extract for $15 \mathrm{~min}$ before being submitted to free radicals produced by a final $50 \mathrm{mM}$ solution of 2,20-azobis (2-amidinopropane) dihydrochloride (AAPH). Diluted blood samples without and in the presence of different amounts of the extract were submitted to organic free radicals produced at $37^{\circ} \mathrm{C}$ under air atmosphere from the thermal decomposition of a $50 \mathrm{mM}$ solution of AAPH. Hemolysis was recorded using a $96-$-well microplate reader by measuring the optical density decay at $450 \mathrm{~nm}$ (Laboratoires Spiral, France). The results were expressed as the percentage increase in KRL value, which is the time required to reach $50 \%$ hemolysis compared to the control blood. A range from 0 to $100 \mathrm{mg} / \mathrm{L}$ of Trolox ${ }^{\circledR}(\mathrm{MW} 250.29 \mathrm{~g} / \mathrm{mole})$, a water-soluble analogue of vitamin E, enabled us to standardize the global antioxidant capacity of the product compared to vitamin E. Mean values of three independent determinations were used for the calculation.

\section{Hematochemical parameters}

Total cholesterol, high-density lipoprotein (HDL) cholesterol, triglycerides, glucose and urea were determined by enzymatic spectrophotometric assay (Alfa Wasserman, Milano, Italy). The concentration of low-density lipoprotein (LDL) cholesterol was calculated using the Friedewald equation according to Johnson et al. (1997).

\section{Oxidative status}

The serum reactive oxygen metabolite (ROM) was determined using a spectrophotometric assay ("D-Roms test” Diacron s.r.l., Grosseto, Italy). The D-Roms test is based on the concept that the amount of organic hydroperoxides present in serum is related to the free radicals from which they are formed (Cesarone et al., 1999; Alberti et al., 2000). When the serum sample is dissolved in an acidic buffer, the hydroperoxides react with the transition metal ions freed from the proteins in the acidic medium and are converted to alkoxy and peroxy radicals. These newly-formed radicals are able to oxidize an additive ( $N, N$-diethyl-para-phenylendiamine) to the 
corresponding radical cation. The concentration of this persistent species can be easily determined through spectrophotometric procedures (absorption at $505 \mathrm{~nm}$ ). The results are expressed in U CARR (Carratelli Units) where 1 U CARR corresponds to $0.024 \mathrm{mmol} / 1 \mathrm{H}_{2} \mathrm{O}_{2}$ or $0.8 \mathrm{mg} / \mathrm{L} \mathrm{H}_{2} \mathrm{O}_{2}$.

\section{Serum immunoglobulin concentration}

Serum concentrations of class $\mathrm{G}(\mathrm{IgG})$ and A (IgA) immunoglobulin were measured at T0 and T56 using the ELISA method, as described by the manufacturer (Bethyl, Montgomery, TX). Briefly, plasma samples were diluted 1:4000 and 1:60,000 to detect IgA and IgG, respectively, in Tris-buffered saline and added to plates coated with class specific immunoglobulin pig antibody.

The different subsets were detected with the appropriate peroxidase anti-pig IgA or IgG (Bethyl) and were quantified with reference to standard curves constructed with known amounts of pig immunoglobulin subsets. Absorbance was read at $450 \mathrm{~nm}$ using an ELISA plate reader (Spectra thermo, Tecan, NC, USA).

\section{Statistical analyses}

All parameters were analyzed using SPSS (SPSS/PC Statistics 24 SPSS Inc., IBM). Live weight and immunoglobulin data were analyzed by GLM (General Linear Model) procedure with treatment as the main effect and the value at the beginning of the trial entered as a covariate. Differences in means were compared according to Bonferroni Multiple Comparisons. Biochemical parameters and serum oxidative status were analyzed by repeated measure analysis of variance (ANOVA) to assess the main effect of treatment and time and value at the beginning of the trial entered as a covariate. Pen was the experimental unit for the productive performance. Piglet was considered the experimental unit of all serum metabolites and immunological variables. Data are presented as means \pm SEM, and a value of $\mathrm{P} \leq 0.05$ is used to indicate statistical significance.

\section{Results}

\section{Antioxidant activity of plant extract}

The results underline that teupolioside from the cell culture of Ajuga reptans has an important antioxidant capacity in vitro, which increases linearly with the dose of the extract up to a concentration of $100 \mathrm{mg} / \mathrm{L}$ (Figure 2). The plant extract from the cell culture of Ajuga reptans (standardized at 50\% in teupolioside) showed an antioxidant activity equivalent to $3.73 \mu$ moles of Trolox per mg of extract.

\section{Growth performance}

The piglets' growth parameters in relation to dietary treatments are reported in Table 2. At the end of the experimental trial, group T2 showed a higher $(\mathrm{P}<0.05)$ body weight compared to the others ( $\mathrm{C}$ and $\mathrm{T} 1)$. Therefore, also the ADG tended to be higher $(\mathrm{P}<0.10)$ in piglets fed with the highest dosage of teupolioside $(\mathrm{T} 2)$. The gain to feed ratio and ADFI were unaffected $(\mathrm{P}>0.05)$ by dietary treatments. No dif- 
ferences among experimental groups were observed in piglet's health status during all the experimental trial.

Table 2. Growth performances of piglets fed control diet or diet supplemented with biotechnological plant extract containing teupolioside

\begin{tabular}{l|c|c|c|c}
\hline & \multicolumn{3}{|c|}{ Dietary Treatment $^{2}$} & \multirow{2}{*}{ P-value } \\
\cline { 2 - 3 } & Control & T1 & T2 & \\
\hline Parameters ${ }^{1,3}$ & & & \\
final BW (kg) & $29.8 \pm 0.54 \mathrm{a}$ & $29.1 \pm 0.55 \mathrm{a}$ & $31.4 \pm 0.56 \mathrm{~b}$ & 0.016 \\
ADG (g/d) & $386 \pm 9.4$ & $380 \pm 10.6$ & $414 \pm 11.5$ & 0.057 \\
G:F (kg/kg) & $0.495 \pm 0.04$ & $0.509 \pm 0.05$ & $0.513 \pm 0.06$ & 0.853 \\
ADFI (kg/day) & $0.782 \pm 0.06$ & $0.747 \pm 0.08$ & $0.748 \pm 0.07$ & 0.134 \\
\hline
\end{tabular}

${ }^{1}$ Data are reported as mean \pm standard error of the mean $(n=5)$.

${ }^{2} \mathrm{~T} 1$ - diet supplemented with plant extract to supply $5 \mathrm{mg}$ teupolioside $/ \mathrm{kg}$ feed, $\mathrm{T} 2$ - diet supplemented with plant extract to supply $10 \mathrm{mg}$ teupolioside $/ \mathrm{kg}$ feed.

${ }^{3} \mathrm{BW}$ - body weight; ADG - average daily gain; G:F - gain to feed ratio; ADFI - average daily feed intake. $\mathrm{a}, \mathrm{b}-$ values in rows with different letters differ significantly $(\mathrm{P} \leq 0.05)$.

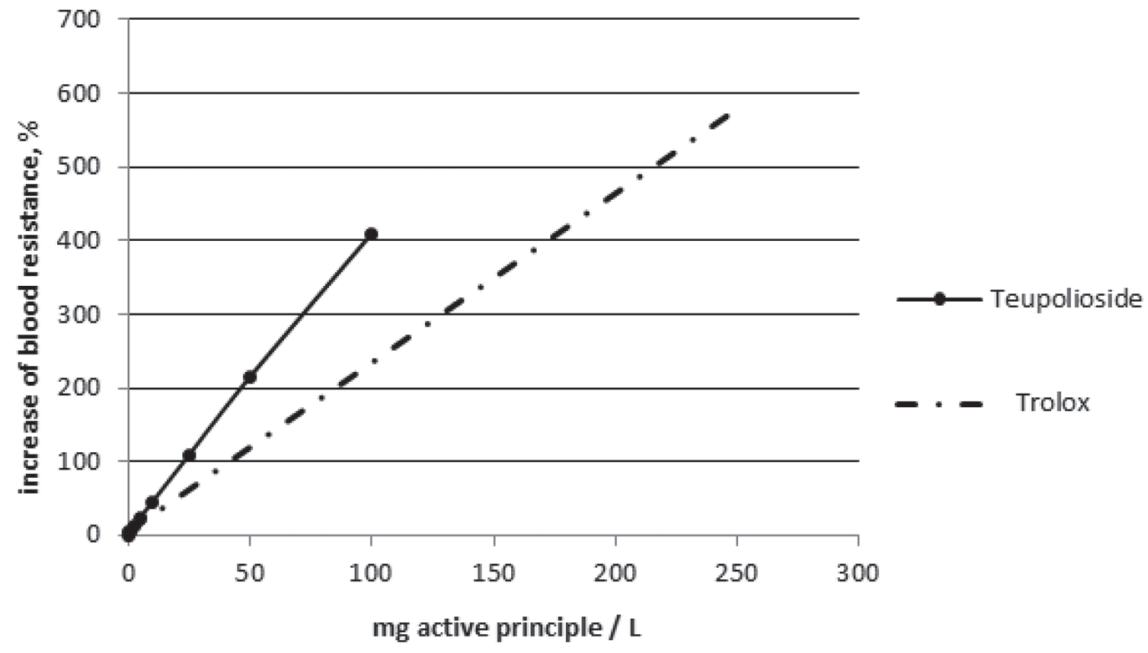

Figure 2. Antioxidant activity of teupolioside measured by biological test Kit Radicaux Libres (KRL)

\section{Oxidative status}

A significant difference in the effect of dietary treatment $(\mathrm{P}=0.037)$ was found in d-ROM production between the control and treatment groups at the end of the trial (Table 3). No significant differences were observed for the time effect $(\mathrm{P}=0.860)$ and the time $\times$ treatment effect $(\mathrm{P}=0.868)$.

\section{Immune parameters}

Dietary supplementation with the plant extract increased $(\mathrm{P}=0.001)$ the IgG serum concentration in T1 and T2 groups compared to control $(8.38 \pm 0.61 \mathrm{~g} / \mathrm{L}$ in control vs $11.77 \pm 0.62 \mathrm{~g} / \mathrm{L}$ and $11.79 \pm 0.56 \mathrm{~g} / \mathrm{L}$ in groups $\mathrm{T} 1$ and $\mathrm{T} 2$, respectively). Fi- 
gure 3 provides the descriptive analysis (box plot) of IgG serum concentration after 56 days of dietary supplementation with biotechnological plant extract. The IgA serum concentration was unaffected $(\mathrm{P}=0.260)$ by dietary treatments $(0.64 \pm 0.09 \mathrm{~g} / \mathrm{L}$ in control $v s 0.65 \pm 0.01 \mathrm{~g} / \mathrm{L}$ and $0.83 \pm 0.09 \mathrm{~g} / \mathrm{L}$ in groups $\mathrm{T} 1$ and $\mathrm{T} 2$, respectively).

Table 3. Serum biochemical parameters of piglets fed control diet or diet supplemented with biotechnological plant extract containing teupolioside (T1 and T2)

\begin{tabular}{|c|c|c|c|c|c|}
\hline \multirow{2}{*}{ Measure $^{1}$} & \multicolumn{3}{|c|}{ Dietary Treatment ${ }^{2}$} & \multicolumn{2}{|c|}{ P-value } \\
\hline & Control & $\mathrm{T} 1$ & $\mathrm{~T} 2$ & Time & Treatment \\
\hline \multicolumn{6}{|c|}{ HDL cholesterol $\left(\mathrm{mmol} / \mathrm{L}^{3}\right)$} \\
\hline Day 14 & $0.341 \pm 0.021$ & $0.380 \pm 0.021$ & $0.383 \pm 0.020$ & \multirow[b]{2}{*}{0.810} & \multirow[b]{2}{*}{0.793} \\
\hline Day 56 & $0.431 \pm 0.013$ & $0.413 \pm 0.013$ & $0.415 \pm 0.012$ & & \\
\hline \multicolumn{6}{|c|}{ Total cholesterol (mmol/L) } \\
\hline Day 14 & $0.944 \pm 0.033$ & $0.972 \pm 0.034$ & $0.909 \pm 0.033$ & \multirow[b]{2}{*}{0.661} & \multirow{2}{*}{0.463} \\
\hline Day 56 & $1.192 \pm 0.084$ & $1.200 \pm 0.084$ & $1.117 \pm 0.083$ & & \\
\hline \multicolumn{6}{|c|}{ LDL cholesterol $\left(\mathrm{mmol} / \mathbf{L}^{3}\right)$} \\
\hline Day 14 & $0.462 \pm 0.041$ & $0.448 \pm 0.040$ & $0.438 \pm 0.035$ & \multirow[b]{2}{*}{0.942} & \multirow[b]{2}{*}{0.147} \\
\hline Day 56 & $0.672 \pm 0.024$ & $0.701 \pm 0.023$ & $0.718 \pm 0.020$ & & \\
\hline \multicolumn{6}{|c|}{ Glucose $(\mathrm{mmol} / \mathrm{L})$} \\
\hline Day 14 & $4.78 \pm 0.26$ & $4.30 \pm 0.26$ & $4.19 \pm 0.26$ & \multirow[b]{2}{*}{0.234} & \multirow[b]{2}{*}{0.341} \\
\hline Day 56 & $3.87 \pm 0.30$ & $4.11 \pm 0.30$ & $3.62 \pm 0.30$ & & \\
\hline \multicolumn{6}{|c|}{ Triglycerides (mmol/L) } \\
\hline Day 14 & $0.67 \pm 0.05$ & $0.70 \pm 0.05$ & $0.51 \pm 0.05$ & \multirow{2}{*}{0.495} & \multirow[b]{2}{*}{0.130} \\
\hline Day 56 & $0.48 \pm 0.03$ & $0.52 \pm 0.35$ & $0.52 \pm 0.03$ & & \\
\hline \multicolumn{6}{|c|}{ Urea $(\mathrm{mmol} / \mathrm{L})$} \\
\hline Day 14 & $2.84 \pm 0.73$ & $2.94 \pm 0.73$ & $3.09 \pm 0.73$ & \multirow[b]{2}{*}{0.152} & \multirow[b]{2}{*}{0.703} \\
\hline Day 56 & $7.55 \pm 1.22$ & $7.35 \pm 1.22$ & $5.92 \pm 1.22$ & & \\
\hline \multicolumn{6}{|c|}{ d-ROM (U carr) } \\
\hline Day 14 & $433 \pm 9.0$ & $415 \pm 8.1$ & $414 \pm 7.2$ & 0.860 & 0.037 \\
\hline Day 56 & $528 \pm 8.2$ & $471 \pm 8.4$ & $485 \pm 8.4$ & & \\
\hline
\end{tabular}

${ }^{1}$ Data are reported as mean \pm standard error of the mean $(n=10)$.

${ }^{2} \mathrm{~T} 1$ - diet supplemented with plant extract to supply $5 \mathrm{mg}$ teupolioside/kg feed, T2 - diet supplemented with plant extract to supply $10 \mathrm{mg}$ teupolioside/ $\mathrm{kg}$ feed.

${ }^{3} \mathrm{HDL}$ - high density lipoprotein, LDL - low density lipoprotein.

\section{Biochemical parameters}

The serum biochemical parameter of piglets fed the control or plant extract supplemented diet are reported in Table 3. Dietary treatment and sampling time did not affect $(\mathrm{P}>0.05) \mathrm{HDL}, \mathrm{LDL}$ and total cholesterol, glucose, triglycerides and urea. No significant differences were observed in the time $\times$ treatment effect $(\mathrm{P}>0.05)$. Data fall within the reference values for all the parameters analyzed. 


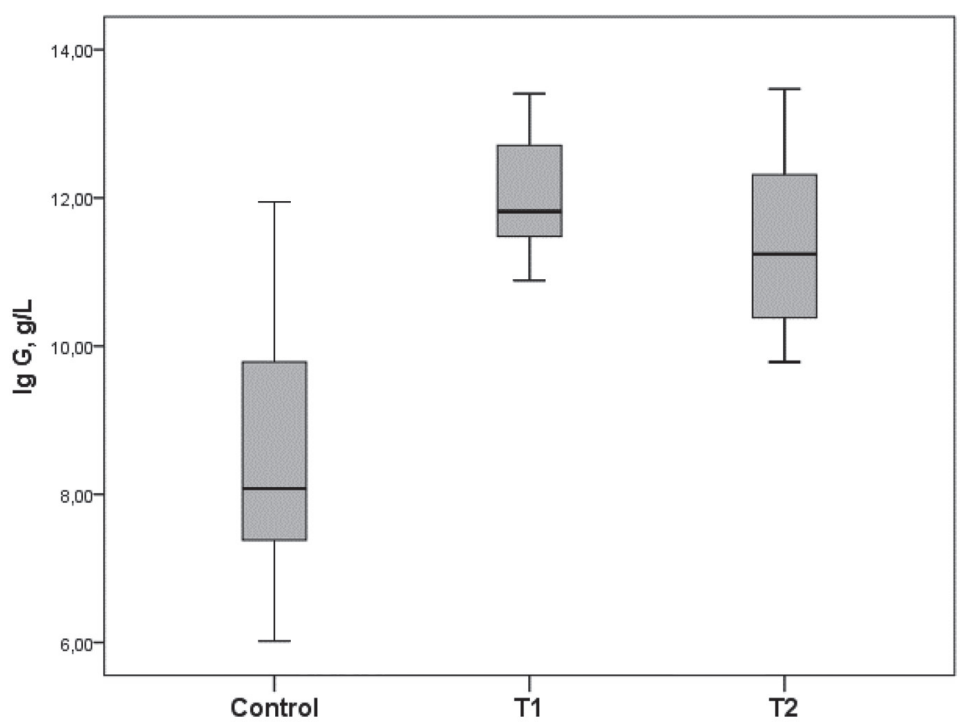

$n=10$; T1, diet supplemented with plant extract to supply $5 \mathrm{mg}$ teupolioside/kg feed, T2, diet supplemented with plant extract to supply $10 \mathrm{mg}$ teupolioside $/ \mathrm{kg}$ feed.

Figure 3. Boxplot of serum IgG in piglets fed control diet or diet supplemented with biotechnological plant extract titrated in teupolioside (T1 and T2 groups) after 56 days of dietary treatment

\section{Discussion}

Regarding phenylpropanoids, many studies have been conducted on several bioactive principles in livestock, but few data are available on plant extracts containing teupolioside. An in vitro study reported that teupolioside has demonstrated anti-inflammatory, anti-oxidant and chelating properties (Korkina et al., 2006). Pastore et al. (2009) also reported that teupolioside could decrease the expression of proinflammatory cytokine which was correlated with the antioxidant, scavenging, and ironchelating activities of this polyphenol (Korkina et al., 2006).

In the present study a higher antioxidant activity of teupolioside was observed in comparison with the vitamin E soluble analogue (Trolox). The KRL test could be a promising approach which allows a dynamic evaluation of the overall antioxidant activity of the plant extract against oxidative stress in a biological system (Maghin et al., 2016).

At weaning, piglets have to deal with many changes and nutritional, environmental and immunological stresses (Le Dividich and Sève, 2000; Montagne et al., 2007). The use of natural supplements in animal nutrition is a good way to improve piglet health and performance as well as to increase the sustainability of the pig sector. In recent years, plant extracts have attracted interest as an innovative dietary strategy to replace antimicrobials (Cheng et al., 2014). The review of Cheng et al. (2014) 
reported that in pig dietary supplementation with some phytogenic additives, such as oregano, cinnamon, Mexican pepper, thyme, garlic extract and Camellia sinensis can modulate intestinal pathogens and improve growth performance. No previous study has reported the effects of dietary supplementation with a biotechnological extract of Ajuga reptans containing teupolioside.

The present results showed an improvement in final weight and ADG in piglets fed the high dosage of biotechnological plant extract (T2). These results agree with other studies reporting that dietary natural extracts containing polyphenols improve growth performance in post weaning piglets (Maass et al., 2005; Devi et al., 2015). In the first study, dietary supplementation with $1.8 \%$ of Echinacea purpurea cobs positively affects feed conversion in post weaning piglets. In the second one, dietary supplementation with $0.05 \%$ of clove, cinnamon and fenugreek mixture increase piglets' ADG compared to dietary supplementation with antimicrobials and organic acid.

The effects of PPG dietary supplementation on growth performance in livestock are conflicting. In previous studies, supplementation with a water-soluble extract of Verbenaceae (Lippia spp.) leaves containing the PPG verbascoside, had a positive effect on growth performance in suckling lambs (Casamassima et al., 2009). On the other hand, no effect on growth performance was reported in pigs, broilers, hares and horses with a supplementation of $5 \mathrm{mg}$ verbascoside $/ \mathrm{kg}$ feed (De Marco et al., 2015; Rossi et al., 2013; Rossi et al., 2017; Vizzarri et al., 2014).

Weaning is a crucial phase in pig husbandry. A sudden dietary change from milk to solid feed induces transient anorexia, intestinal inflammation and unbalanced gut microbiota, which are important causes of post weaning diarrhea and associated infections in piglets (Gresse et al., 2017). In this situation, an imbalance between reactive oxygen species production and their neutralization by the antioxidant system of the organism has also been observed, leading to oxidative stress which negatively affects piglet health (Rossi et al., 2009; Buchet et al., 2017). This situation is more serious in the presence of post weaning diarrhea. In fact it has been reported that inflammation increases oxidative stress in animals (Lykkesfeldt and Svendsen, 2007). In addition, a study performed by Sauerwein et al. (2007) highlighted that the high $\mathrm{d}$-ROMs values in the first week after weaning are associated with decreasing growth rates.

The present data show that serum d-ROMs in piglets fed with teupolioside was lower than the controls, thus demonstrating the antioxidant activity of the active principle. These data agree with the literature that reports a reduction in d-ROM production or an enhancement in antioxidant status in livestock after dietary supplementation with Verbenaceae (Lippia spp.) extract containing verbascoside (Casamassima et al., 2012; Casamassima et al., 2013; Rossi et al., 2013). In fact, polyphenols prevent the oxidation of low-molecular-weight antioxidants, such as vitamin A and E, thus increasing their amount of serum (Palazzo et al., 2011; Paszkiewicz et al., 2012). Additionally, previous studies in piglets have reported that dietary supplementation with verbascoside can restore liver antioxidant status induced by the high intake of $n$-6 PUFA, leading to oxidative stress (Di Giancamillo et al., 2015). As recently reported in the literature, polyphenols protect cells against oxidative stress 
caused by free radicals through several mechanisms, thus reducing the risk of associated diseases (Lipiński et al., 2017).

The polyphenol metabolism has not been fully clarified and its availability is related to its chemical characteristics and functional groups (Landete, 2012). The present data showed that blood biochemical parameters were not affected by dietary integration with the biotechnological extract, in agreement with a previous study in weaned piglets fed Lippia citrodora extract containing verbascoside (Pastorelli et al., 2012). On the other hand, other studies in livestock have reported that dietary supplementation with a plant extract containing verbascoside improved the lipid blood profile, decreasing total cholesterol, LDL cholesterol and triglycerides (Palazzo et al., 2011; Casamassima et al., 2014; D’Alessandro et al., 2017).

Several studies have reported that dietary polyphenols from several sources have an immunomodulatory effect on immune cell populations (Cuevas et al., 2013). One important lymphocytes class are B cells which are involved in humoral immunity and produce immunoglobulins. In the literature, the effects of a natural extract containing polyphenols on immunoglobulin production have not been described sufficiently in depth. An in vitro study on human peripheral blood mononuclear cells reported that resveratrol did not affect IgM and IgG production (Zunino and Storms, 2009). Other in vitro studies have reported that polyphenols from several sources are able to modulate B cell function, downregulating IgE and IgG production (Sanbongi et al., 1997; Hassanain et al., 2010).

Our data showed that dietary supplementation with a biotechnological plant extract increased serum IgG without affecting $\operatorname{IgA}$ production. The modulation in immunoglobulin production by a dietary supplement with a natural extract in post weaning piglets has been reported by Pastorelli et al. (2012). The authors reported that dietary supplementation with different amounts of plant extract titrated in verbascoside increased both serum IgG and IgA concentrations, thus reflecting the active synthesis of antibodies by the piglets' immune system (Kanitz et al., 2004).

\section{Conclusion}

Overall, the results suggest that dietary supplementation with a biotechnological extract of Ajuga reptans containing teupolioside in the post-weaning phase improves piglet health. In fact, piglets fed the high dosage of teupolioside showed a higher body weight at the end of the trial. In addition, dietary supplementation with teupolioside in piglets positively affected serum d-ROM production and IgG title, without affecting other biochemical parameters. These data demonstrate the antioxidant and immunomodulant effects of the biotechnological extract of Ajuga reptans containing teupolioside. Further studies are needed to explore the mechanism of action of teupolioside and to clarify the optimal length and dosage of the dietary treatment.

\section{Acknowledgments}

This project was funded by University of Milan.

\section{Conflict of interest}

The authors declare no conflicts of interest. 


\section{References}

Alberti A., Bolognini L., Macciantelli D., Caratelli M. (2000). The radical cation of N, N-diethyl-para-phenylendiamine: a possible indicator of oxidative stress in biological samples. Res. Chem. Intermediat., 26: 253-267.

B rüs s ow H. (2017). Adjuncts and alternatives in the time of antibiotic resistance and in-feed antibiotic bans. Microb. Biotechnol., 10: 674-677.

B u chet A., B e 11 o c C., L e bl an c-M aridor M., M erlot E. (2017). Effects of age and weaning conditions on blood indicators of oxidative status in pigs. PLoS One, 12: e0178487.

C a s a m a s s i m a D., P a la z zo M., Presutt i T., C ole 11 a G.E. (2009). Productive performances, plasmatic oxidative status and some blood parameters in suckling lambs supplemented with verbascoside. It. J. Anim. Sci., 8: 668.

Cas a ma s s i m a D., P a lazzo M., M artem uc ci G., Vizzarri F., Corino C. (2012). Effects of verbascoside on plasma oxidative status and blood and milk production parameters during the peripartum period in Lacaune ewes. Small Rumin. Res., 105: 1-8.

Cas a massima D., Pa lazzo M., Vizzarri F., C inone M., Corino C. (2013). Effect of dietary phenylpropanoid glycoside-based natural extracts on blood parameters and productive performance in intensively-reared young hares. Czech J. Anim. Sci., 58: 270-278.

Cas amassima D., Nardoia M., Palazzo M., Vizzarri F., D'Alessandro A.G., C or i n o C. (2014). Effect of dietary extruded linseed, verbascoside and vitamin E supplements on yield and quality of milk in Lacaune ewes. J. Dairy Res., 81: 485-493.

Cesarone M.R., B elc aro G., Caratelli M., Cornelli U., D e Sanctis M.T., Incandela L., Barsott R., Terranova R., Nicolaides A. (1999). A simple test to monitor oxidative stress. Intern. Angiol., 2: 127-130.

Cheng G., H a o H., Xi e S., X u W., D a i M., H u a n g L., Yu an Z. (2014). Antibiotic alternatives: the substitution of antibiotics in animal husbandry? Front. Microbiol., 5: 217.

Cu ev a s A., S a a ved r a N., S a 1 a z a r L.A., A b d a 11 a D.S.P. (2013). Modulation of immune function by polyphenols: possible contribution of epigenetic factors. Nutrients, 5: 2314-2332.

D a 1 To s o R., M e la ndri F. (2009). Biotechnologically produced botanical ingredients Ajuga reptans extract titrated in teupolioside. Nutrafoods, 8: 29-36.

D' A les s andro A.G., Vizzarri F., Pa lazzo M., Marte mu c ci G. (2017). Dietary verbascoside supplementation in donkeys: effects on milk fatty acid profile during lactation, and serum biochemical parameters and oxidative markers. Animal, 11: 1505-1512.

De Marco M., Salcedo W.L., Pastorelli G., Rossi R., Corino C., Bergagna S., Mellia E., Gennero M.S., Biasibetti E., Capucchio M.T., Nurisso S., Taranto la M., F or neris G., S c hi a v o n e A. (2015). Effects of verbascoside supplemented diets on growth performance, blood traits, meat quality, lipid oxidation and histological features in broiler chickens. It. J. Anim. Sci., 14: 172-178.

D e m b it s k y V.M. (2005). Astonishing diversity of natural surfactants: 5. Biologically active glycosides of aromatic metabolites. Lipids, 40: 869-900.

D e vi S.M., L e e S.I., K i m I.H. (2015). Effect of phytogenics on growth performance, fecal score, blood profiles, fecal noxious gas emission, digestibility, and intestinal morphology of weanling pigs challenged with Escherichia coli K88. Pol. J. Vet. Sci., 18: 557-564.

Di Giancamillo A., Rossi R., Pastorelli G., Deponti D., Carollo V., Cas a mas s i m a D., D o m e n e g h in i C., C or in o C. (2015). The effects of dietary verbascoside on blood and liver oxidative stress status induced by a high n-6 polyunsaturated fatty acids diet in piglets. J. Anim. Sci., 93: 284-959.

Di Paola R., Esposito E., Mazzon E., Riccardi L., Caminiti R., Dal Toso R., Press i G., Cuzzocrea S. (2009). Teupolioside, a phenylpropanoid glycosides of Ajuga reptans, biotechnologically produced by IRB plant cell line, exerts beneficial effects on a rodent model of colitis. Biochem. Pharmacol., 77: 845-857.

European Surveillance of Veterinary Antimicrobial Consumption (2016). Sales of veterinary antimicrobial agents in 29 European countries in 2014. Trends from 2011 to 2014. VI ESVAC report. 14.10. 2016. 
European Patent EP 1997501 A2. Extracts from Ajuga reptans cell lines, their preparation and use. Date of publication: 03.12.2008 Bulletin 2008/49.

Food and Drug Administration (2013). Animal Drug User Fee Act (ADUFA) public meeting. Food and Drug Administration Center for Veterinarian Medicine.18.12 2012.

Gh e i s a r M.M., K i m M. (2018). Phytobiotics in poultry and swine nutrition - a review. It. Anim. Sci., 17: 92-99.

Gresse R., Chaucheyras-Durand F., Fleury M.A., Van de Wiele T., Forano E., B l an quet - D i o t S. (2017). Gut microbiota dysbiosis in postweaning piglets: understanding the keys to health. Trends Microbiol., 25: 851-873.

Has sanain E., Silverberg J.I., Norowitz K.B., Chice S., Bluth M.H., Brody N., J o k s R., D u rk in H.G., S m i th - N o r ow it z T.A. (2010). Green tea (Camelia sinensis) suppresses B cell production of IgE without inducing apoptosis. Ann. Clin. \& Lab. Sci., 40: 135-143.

Johns on R., McNutt P., Mac Mahon S., Robs on R. (1997). Use of the Friedewald formula to estimate LDL-cholesterol in patients with chronic renal failure on dialysis. Clin. Chem., 11: 2183-2184.

K a m e 1 C. (2001). Tracing modes of action and the roles of plant extracts in non-ruminants. In: Recent Advances in Animal Nutrition, Garnsworthy P.C., Wiseman J. (eds), pp. 135-150.

Kanitz E., Tuchscherer M., Puppe B., Tuchs cherer A., S tabenow B. (2004). Consequences of repeated early isolation in domestic piglets (Sus scrofa) on their behavioural, neuroendocrine, and immunological responses. Brain Behav. Immun., 18: 35-45.

Korkina L.G., Mikhalchik E., S u prun M.V., P a store S., Dal Tos o R. (2006). Molecular mechanisms underlying wound healing and anti-inflammatory properties of naturally occurring biotechnologically produced phenylpropanoid glycosides. Cell. Mol. Biol., 53: 78-83.

L a n d e t e J.M. (2012). Updated knowledge about polyphenols: functions, bioavailability, metabolism, and health. Crit. Rev. Food Sci. Nutr., 52: 936-948.

L e Dividich J., S è ve B. (2000). Effects of under feeding during the weaning period on growth, metabolism, and hormonal adjustments in the piglet. Domestic Anim. Endocrinol., 19: 63-74.

Li piński K., Mazur M., Antoszki ew icz Z., Purwin C. (2017). Polyphenols in monogastric nutrition - a review. Ann. Anim. Sci., 17: 41-58.

L o oft T., Johns on T.A., A 11 e n K.H., B a yle s D.O., A $1 \mathrm{t}$ D.P., S t e d t feld R.D., S u 1 W.J., Stedtfeld T.M., Chai B., Cole J.R., Hashsham S.A., Tiedje J.M., Stanton T.B. (2012). In-feed antibiotic effects on the swine intestinal microbiome. Proc. Natl. Acad. Sci., 109: 1691-1696.

Lyk kes fe ld t J., S vendse n O. (2007). Oxidants and antioxidants in disease: Oxidative stress in farm animals. Vet. J., 173: 502-511.

M a a s s N., B a u e r J., P a u 1 i c k s B.R., B öh me r B.M., R o th-M a i e r D.A. (2005). Efficiency of Echinacea purpurea on performance and immune status in pigs. J. Anim. Physiol. Anim. Nutr., 89: 244-252.

M a g h in F., R o s s i R., Pros t M., C or in o C. (2016). Biological system to assess the antioxidant capability of plant extracts. Proc. Nutriox meeting. Kaiserslautern, Germany, 21-23.09.2016.

Montagne L., Boudry G., Favier C., Le Huërou-Luron I., Lallès J.P., Sève B. (2007). Main intestinal markers associated with the changes in gut architecture and function in piglets after weaning. Br. J. Nutr., 97: 45-57.

National Research Council (1998). Nutrient Requirements of Swine. 10th rev. eds, National Academy Press: Washington, DC.

Palazzo M., Vizzarri F., Cinone M., Corino C., Cas a massima D. (2011). Assessment of a natural dietary extract, titrated in phenylpropanoid glycosides, on blood parameters and plasma oxidative status in intensively reared Italian hares (Lepus corsicanus). Animal, 5: 844-850.

Pastore S., Potapovich A., Kostyuk V., Mariani V., Lulli D., D e Luca C., Korkin a L. (2009). Plant polyphenols effectively protect HaCaT cells from ultraviolet C-triggered necrosis and suppress inflammatory chemokine expression. Ann. New York Acad. Sci., 1171: $305-313$.

Pastorelli G., Rossi R., Corino C. (2012). Influence of Lippia citriodora verbascoside on growth performance, antioxidant status, and serum immunoglobulins content in piglets. Czech J. Anim. Sci., 57: 312-322. 
Pas zki ew i c z M., B u dzy n ska A., R o za lsk a B., S a d ow s ka B. (2012). The immunomodulatory role of plant polyphenols (in Polish). Postep. Hig. Med. Dosw., 66: 637-646.

Pros t M. (1992). Process for the determination by means of free radicals of the antioxidant properties of a living organism or potentially aggressive agents. In: US Patent 5,135,850.

R o s s i R., P a s t or e 11 i G., C a n n a t a S., C or in o C. (2009). Effect of weaning on total antiradical activity in piglets. Proc. of the XVIII Animal Science and Production Association Congress, Palermo, Italy 9-12.06.2009, p. 673.

R o s s i R., P a s t or e 11 i G., C or in o C. (2013). Application of KRL test to assess total antioxidant activity in pigs: sensitivity to dietary antioxidants. Res. Vet. Sci., 94: 372-377.

Rossi R., Ratti S., Pastorelli G., Maghin F., Martemucci G., Casamas sima D., D' A les s a ndro A.G., C orino C. (2017). Effect of dietary plant extract on meat quality and sensory parameters of meat from Equidae. J. Sci. Food Agric., 97: 4690-4696.

S a n bong i C., Suzuki N., S a k an e T. (1997). Polyphenols in chocolate, which have antioxidant activity, modulate immune functions in humans in vitro. Cell. Immunol., 177: 129-136.

S a n gw a n N.S., F a r o o qi A.H.A., Sh a bih F., S a n g w a n R.S. (2001). Regulation of essential oil production in plants. Plant Growth Reg., 34: 3-21.

S a u e rw e in H., S c h m it z S., H is s S. (2007). Effects of a dietary application of a yeast cell wall extract on innate and acquired immunity, on oxidative status and growth performance in weanling piglets and on the ileal epithelium in fattened pigs. J. Anim. Physiol. Anim. Nutr., 91: 369-380.

Van Boeckel T.P., Brower C., Gilbert M., Grenfell B.T., Levin S.A., Robins o n T.P., Teillant A., Laxminarayan R. (2015). Global trends in antimicrobial use in food animals. Proc. Nat. Acad. Sci., 112: 5649-5654.

Vizzarri F., Nardo i a M., Pa lazzo M. (2014). Effect of dietary Lippia citriodora extract on productive performance and meat quality parameters in hares (Lepus europaeus Pall.). Archiv. Tierzucht, 57: 1-7.

World Health Organization (WHO) (2017). Stop using antibiotics in healthy animals to prevent the spread of antibiotic resistance, 07 November, Geneve.

Z u n i n o S.J., S t o r m s D.H. (2009). Resveratrol alters proliferative responses and apoptosis in human activated B lymphocytes in vitro. J. Nutr., 139: 1603-1608.

Received: 21 II 2019

Accepted: 4 IV 2019 